\title{
Work-related asthma: A case-based guide
}

\author{
Susan M Tarlo MB BS FRCPC ${ }^{1}$, André Cartier MD FRCPC FAAAAI ${ }^{2}$, Catherine Lemière MD MSc ${ }^{2}$; on behalf of the \\ Canadian Thoracic Society Asthma Committee
}

\begin{abstract}
SM Tarlo, A Cartier, C Lemière; on behalf of the Canadian Thoracic Society Asthma Committee. Work-related asthma: A case-based guide. Can Respir J 2009;16(6):e57-e61.

Work-related asthma is common yet underdiagnosed. It is a significant cause of morbidity and socioeconomic loss. Diagnosis is often difficult, and requires a strong index of suspicion and careful investigation. The Canadian Thoracic Society has endorsed the recent American College of Chest Physicians consensus statement on work-related asthma. The present document illustrates the advised approach to diagnosis and management of work-related asthma using case-based examples of occupational asthma and work-exacerbated asthma. The main statements of advice from the American College of Chest Physicians consensus statement are reproduced with permission.
\end{abstract}

Key Words: Occupational asthma, Work-exacerbated asthma, Workrelated asthma

Ccupation is an important consideration in the evaluation of patients with asthma (1-5). Asthma can be caused by work (occupational asthma: sensitizer-induced or irritantinduced) or aggravated by work (work-exacerbated asthma). Asthma that is not work-related can also interfere with the ability to work, especially if it is severe or uncontrolled; this, however, will not be discussed further in the present document. All of these situations can result in time lost from work or reduced productivity, and each situation may require a different approach to management. A new consensus statement on work-related asthma has been developed by a panel (approximately one-third of which were Canadian) for the American College of Chest Physicians (ACCP) (5) and received endorsement from the Canadian Thoracic Society. The present article uses two case examples (adapted for illustrative purposes) to demonstrate the approach to diagnosis and management of work-related asthma and the key points presented are consistent with the summary statements from the ACCP consensus document that follow at the end of the present article (reproduced with permission of the ACCP and CHEST) (5).

\section{CASE 1: ILLUSTRATING SENSITIZER-INDUCED OCCUPATIONAL ASTHMA}

A 44-year-old man presents with a three-year history of cough, wheeze and shortness of breath, relieved by a bronchodilator. He had no associated chest pain, but did note itchy, watery eyes, stuffy, runny, itchy nose, sneeze and itchy face associated with his chest symptoms.

\begin{abstract}
Asthme professionnel : Guide par études de cas

L'asthme professionnel est courant, mais sous-diagnostiqué. Il s'agit d'une cause importante de morbidité et de pertes socioéconomiques. Le diagnostic est souvent difficile et requiert un fort indice de suspicion et des analyses rigoureuses. La Société canadienne de thoracologie a appuyé le récent énoncé consensuel de l'American College of Chest Physicians au sujet de l'asthme professionnel. Le présent document illustre l'approche conseillée pour le diagnostic et la prise en charge de l'asthme professionnel à l'aide d'exemples de cas d'asthme professionnel et d'asthme exacerbé en milieu de travail. Les principales recommandations énoncées par l'American College of Chest Physicians dans son document consensuel sont reproduites avec son autorisation.
\end{abstract}

Key points: Adult-onset asthma-like symptoms - be sure to take an occupational history in any such patient. The primary health care provider and specialist should be aware to consider a diagnosis of work-related asthma. Identified barriers to diagnosis of work-related asthma have included a lack of physician inquiry regarding a work association. Rhinitis is commonly associated with occupational asthma. The nasal and eye symptoms described in this case are typical of allergic rhinitis and conjunctivitis, which are more commonly found in immunoglobulin E-mediated allergic responses, rather than low-molecular-weight sensitization.

- He has worked at a plant that processes chicken for a fastfood chain for 10 years. Initially, he worked cutting and deboning chickens but developed a repetitive strain injury. Consequently, he moved to work further down the same line six years previously, checking that pieces had no bones

- Reported exposures: carbon dioxide from freezers, cooking oil fumes, breading dust and chicken meat

Key points: Onset of asthma symptoms during working life; ask about work relationships of symptoms.

- Symptoms are slightly better during the weekends. He wakes up occasionally at night because of cough, wheezing and chest tightness that is relieved by his bronchodilator. His symptoms are worse at work, especially after $3 \mathrm{~h}$ to $4 \mathrm{~h}$ if the breading level is high, particularly for breaded chicken and kebabs

- At times, he has no symptoms at work for two to three weeks, with no identified exposure differences; however, he believed the lack of symptoms was due to less carbon dioxide leaking

${ }^{1}$ Toronto Western Hospital and University of Toronto, Toronto, Ontario; ${ }^{2}$ Hôpital du Sacré Coeur de Montréal and Université de Montréal, Montreal, Quebec

Correspondence: Dr Susan M Tarlo, Toronto Western Hospital, East Wing 7-449, 399 Bathurst Street, Toronto, Ontario M5T 2 S8.

Telephone 416-603-5177, fax 416-603-6763, e-mail susan.tarlo@utoronto.ca 


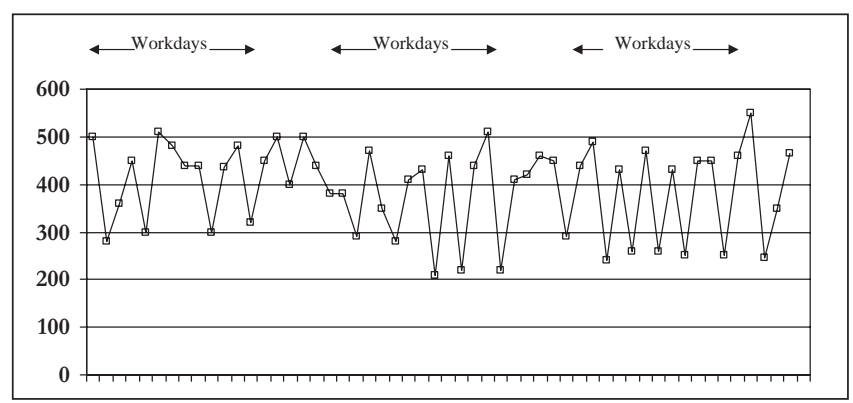

Figure 1) Serial peak expiratory flow readings ( $\mathrm{L} / \mathrm{min}$, four times a day) recorded by the patient

from the freezer at those times. He noted that his breathing was more laboured when he was exposed to higher carbon dioxide levels.

- During a six-month absence from work, symptoms cleared completely, but recurred when he returned

- No respirator worn (he has a beard and does not wish to shave it)

- Other employees have similar symptoms. There is no union at work and he states that the health and safety committee has not been interested in helping

- He is taking an inhaled corticosteroid regularly and short-acting bronchodilator as needed, with benefit. His physical examination is normal

Key point: Symptoms that suggest asthma is worse at work should be objectively investigated to confirm that they are due to asthma, and if confirmed, to determine whether they are due to occupational asthma rather than work-exacerbated asthma.

- Pulmonary function testing was arranged at the end of a work week

- Forced expiratory volume in $1 \mathrm{~s}\left(\mathrm{FEV}_{1}\right)$ prebronchodilator 2.42 L (61\% predicted), postbronchodilator $3.07 \mathrm{~L}$ (77\% predicted) - a $27 \%$ increase

- Forced vital capcity (FVC) $93 \%$ predicted pre- and postbronchodilator

- Lung volumes, diffusion capacity $\left(\mathrm{D}_{\mathrm{L}} \mathrm{CO}\right)$ normal

Key points: Objective evidence of asthma has been shown, but other tests are needed, when possible, to more effectively determine the relationship with work (ie, work exacerbation versus occupational asthma). Referral to a centre specialized in occupational lung disease is suggested for these tests. In some provinces, this may be facilitated by the provincial workers' compensation board, with early initiation of a claim.

- Skin prick tests

- Dust and dust mite 4+, tree and grass 3+, ragweed, Cladosporium species, cat, dog, horse $2+$ each

- Chicken coating breading mix from work 4+(10 mm $\times 6 \mathrm{~mm})-$ negative in a control subject

- Chicken (food allergen extract) 2+, milk, wheat, egg, oregano, coriander - all negative

Key point: The patient is atopic and also has a positive allergy skin test to a workplace allergen. In a patient with definite asthma and worsening of symptoms at work, the positive skin test to the specific agent (chicken coating breading mix or, possibly, chicken itself, in this case) is supportive (although not diagnostic) of occupational asthma.
- He was afraid to ask for Material Safety Data Sheets (MSDSs); therefore, the specific agents present in the breading mix could not be identified

Key point: MSDSs should list known hazardous components and be available to every worker. There are limitations and MSDSs may not list proteins and other sensitizers, such as diisocyanates when they are at low concentrations (less than $0.1 \%)$, although potentially harmful.

- The patient was asked to perform serial peak expiratory flow readings in triplicate, four times per day (preshift, midshift, end of shift and bedtime, with similar times when not working), over several weeks (Figure 1).

Key point: Peak flow recordings are best interpreted when recordings are made during periods of one week or more away from work, as well as weeks at work because, as in this patient, weekends may not be long enough to show improvement. Symptoms and bronchodilator use should also be recorded in triplicate on diary sheets at least four times daily. Interpretation of the peak flow results also needs consideration of history in determining the probability of work-exacerbated asthma or occupational asthma (more suggestive of occupational asthma in this patient). Careful instruction of the patient is needed (by the physician or asthma educator) and the importance of good effort and compliance needs emphasis to interpret responses.

- A methacholine challenge test at the end of a work week (Thursday afternoon) showed a provocative concentration causing a $20 \%$ fall in $\mathrm{FEV}_{1}\left(\mathrm{PC}_{20}\right)$ of $1 \mathrm{mg} / \mathrm{mL}$ (baseline $\mathrm{FEV}_{1} 2.6 \mathrm{~L}, 79 \%$ predicted) and after six weeks off work (due to a back injury) $\mathrm{PC}_{20}$ improved to $4 \mathrm{mg} / \mathrm{mL}$, (baseline $\mathrm{FEV}_{1} 3.0 \mathrm{~L} ; 90 \%$ predicted; $\mathrm{FEV}_{1} / \mathrm{FVC} 66 \%$ ); he needed no medications while off work. He did not record peak flows because of back pain.

Key points: $A$ threefold or greater change in $\mathrm{PC}_{20}$ methacholine has been reported to be outside the normal range of variability within the same laboratory. Significant improvement in methacholine responsiveness away from work versus at work supports occupational asthma in this patient.

- A diagnosis of occupational asthma was made

- Initiation of a workers' compensation claim was suggested

- There was no job in the company building that was at a greater distance from the breading area

- Likely diagnosis: occupational asthma and rhinoconjunctivitis, most likely from a component of the breading mix. A response to chicken itself was not excluded, and if exact identification of the specific agent was necessary for his future work, a specific challenge would be needed

- Asthma medications were optimized while his compensation claim was pending and until he left the workplace exposure

- The Ministry of Labour was informed to assess the workplace conditions and to determine whether changes could be made to prevent further occupational asthma

Key points: In this patient, the diagnosis of occupational asthma was very likely. In certain circumstances, specific inhalation challenge tests in the laboratory or at work may be necessary to confirm or exclude the diagnosis of occupational asthma, particularly when the peak expiratory flow record is equivocal or if the worker is unable to return to work - this is available in specialized centres 
TABLE 1

\begin{tabular}{|c|c|}
\hline Agent & Where found/uses \\
\hline Diisocyanates & $\begin{array}{l}\text { Spray painting, urethane coatings, foundries, } \\
\text { polyurethane foam }\end{array}$ \\
\hline Flour and cereals & Bakeries, grain handlers \\
\hline Acrylates & Glues, paints \\
\hline Animal proteins & $\begin{array}{l}\text { Laboratory animal care workers, veterinarians, } \\
\text { farmers, }\end{array}$ \\
\hline $\begin{array}{l}\text { Wood dusts (eg, red } \\
\text { cedar, exotic woods) }\end{array}$ & Saw mills, carpenters, woodworkers \\
\hline Natural rubber latex & $\begin{array}{l}\text { Latex gloves and other products - health care } \\
\text { workers }\end{array}$ \\
\hline Colophony & Soldering flux \\
\hline Enzymes & Laboratory workers \\
\hline Crab, shrimp & Fisheries \\
\hline $\begin{array}{l}\text { Metal salts (eg, platinum } \\
\text { salts) }\end{array}$ & Industrial settings \\
\hline
\end{tabular}

across Canada. In the province of Quebec, the performance of specific inhalation challenges is mandatory in the vast majority of cases to prove the diagnosis of occupational asthma.

Induced sputum eosinophil counts compared during work periods and off-work, if available, can also assist diagnosis.

Patients with occupational asthma should be removed from further exposure to the work sensitizer, if possible, only after confirmation of the diagnosis. In cases for which asthma is too poorly controlled or severe to permit initial safe investigations at work, temporary removal from work may be required to achieve optimal asthma control with minimal medication before completing diagnostic investigations at the workplace.

In contrast, individuals with occupational asthma induced by an irritant exposure and those with work-related aggravation of asthma may be able to stay in the same job with optimization of asthma medications and in some cases a reduction in exposure to exacerbating exposures at work.

Physicians should support patients with work-related asthma in their application for appropriate workers' compensation.

The diagnosis of occupational asthma should lead to consideration of other workers in the same workplace. Identification of other workers with occupational asthma, and preventive measures in the workplace may be initiated by notifying appropriate authorities (eg, a ministry of labour or when the patient consents, notifying a company physician).

- This patient had a compensation claim for occupational asthma accepted.

- He left the company and his asthma symptoms cleared completely, although his methacholine response continued to show borderline hyper-responsiveness $\left(\mathrm{PC}_{20} 8 \mathrm{mg} / \mathrm{mL}\right)$.

Key point: The best medical outcome for sensitizer-induced occupational asthma occurs with an early, accurate diagnosis and removal from further exposure to the causative agent.

- Unfortunately, he has not found other employment (six months later) and is being assessed for possible retraining

Key point: There can be a poor socioeconomic outcome from work-related asthma and there is a need for the physician to discuss this - in addition to medical outcomes - with patients who have occupational asthma and work-exacerbated asthma.
TABLE 2

Common examples of agents that cause work-exacerbated asthma

\begin{tabular}{ll}
\hline Agent & Where found/uses \\
\hline $\begin{array}{l}\text { Organic dusts } \\
\text { Inorganic dusts }\end{array}$ & $\begin{array}{l}\text { Farming, animal care laboratories, animal feed } \\
\text { Mining, manufacturing settings, cleaning work, office } \\
\text { renovations }\end{array}$ \\
Fumes & Industrial processes \\
Irritant gases & Ozone (eg, bottling work), sulphur dioxide \\
Temperature & Outdoor work, food refrigeration work, some industrial \\
extremes & settings involving heat \\
Viral infections & Teachers, crowded offices \\
\hline
\end{tabular}

General comments and summary: Primary care providers and respiratory physicians have recognized a need for increased education in occupational lung disease. Work-related asthma is the most common chronic occupational lung disease and is likely to present initially to primary care providers. Common causes of occupational asthma are presented in Table 1. Consideration of this diagnosis and questioning regarding the history of work-related asthma symptoms, along with an occupational exposure history, can lead to early suspicion of the diagnosis and referral for specialist investigation, including confirmation of asthma, work exposure details, objective determination of asthma changes at work versus off work, immunological confirmation of sensitization when applicable, and consideration of more specialized tests such as induced sputum and specific inhalation challenges (in the laboratory or in the workplace). Patients should not quit their job and should continue working before a confirmed diagnosis if it is considered safe. Their asthma should be managed pharmacologically during this process. A workers' compensation claim should be submitted; however, details and requirements differ by province. Coworkers should be considered - notification of the provincial Ministry of Labour and/or a company physician (with the patient's approval) may allow preventive measures to protect other workers. After a diagnosis of occupational asthma due to a sensitizer, early removal from further exposure should be recommended. Although emphasis in the present case has been placed on occupational asthma from a sensitizer, a high irritant exposure can also cause occupational asthma (such as reactive airways dysfunction syndrome) (2).

In addition, it is relatively common for work exposures to exacerbate or aggravate asthma (4) (Table 2) as illustrated in the next case, and this type of asthma should also be considered in individuals with asthma symptoms that are worse when at work.

\section{CASE 2: ILLUSTRATING WORK-EXACERBATED ASTHMA}

A 45-year-old man has worked as a woodworking teacher in high schools for 15 years. He has a history of childhood asthma that improved in his teens but recurred 13 years previously during his summer holidays off school when he was not working and not performing any woodworking at home. His physician objectively documented asthma with spirometry at that time showing mild airflow limitation ( $\left.\mathrm{FEV}_{1} / \mathrm{FVC} 65 \%\right)$, with a $15 \%$ increase in $\mathrm{FEV}_{1}$ following the use of a bronchodilator. There was no acute exposure event at work before the onset of his 


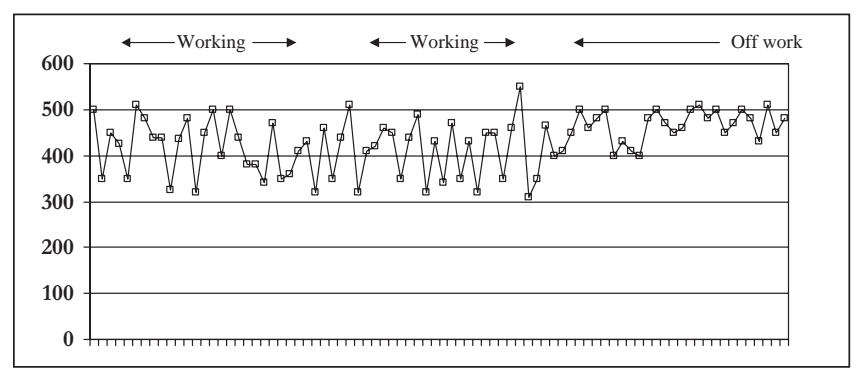

Figure 2) Peak flow readings ( $\mathrm{L} / \mathrm{min}$ ) of a high school woodworking teacher

symptoms at that time. On return to work in September, he noted that the dust from many unrelated woods (pine, maple, ash and oak) exacerbated his symptoms, particularly when he moved to a different school location two years previously, where his woodwork class had less local ventilation and was located next to the welding shop and paint shop area. His need for asthma medications increased and he also began to notice that scented products worn by students would worsen his symptoms in the hallways of the school, which caused associated throat tightness and dysphonia. He was unable to wear respiratory protection because his job required him to give oral instructions to his students. He had no change in his home environment and had positive skin tests to dust mite and cockroach allergens. MSDSs showed potential exposure to multiple respiratory irritants and some potential sensitizers.

Peak expiratory flow readings (Figure 2) showed worsening at work, where he also recorded increased symptoms and improvement in symptoms when he used his short-acting bronchodilator, with a constant dose of his combined inhaled steroid and long-acting bronchodilator. Spirometry revealed a lower $\mathrm{FEV}_{1}$ during the work week ( $75 \%$ predicted) than off work ( $88 \%$ predicted) but his methacholine $\mathrm{PC}_{20}$ was similar: $1.5 \mathrm{mg} / \mathrm{mL}$ at the end of a work week and $2 \mathrm{mg} / \mathrm{mL}$ after three weeks off work during the summer holidays. Induced sputum tests showed 3\% eosinophils at both of these visits.

Diagnosis and management: This patient had recurrent asthma starting outside of his work environment that was exacerbated with exposure to expected irritant agents at work (ie, work-exacerbated asthma). Potentially, he may also have been sensitized to one of several work agents, but he noticed similar symptom exacerbation with dust from several unrelated woods, which was more suggestive of an irritant response instead of a specific response; immunological testing was not feasible, and the lack of additional increase in methacholine response and eosinophil count in induced sputum at work versus off work does not support the diagnosis of occupational asthma. He may also have had a component of irritable larynx syndrome, accounting for symptoms with scented products; consequently, he was referred for otolaryngology evaluation and management.

Dust mite control measures were implemented at home and his pharmacological management was optimized. He was offered a transfer to a different school that had better ventilation and a wood shop that was in a different area from the other industrial shop areas; subsequently, his asthma was well controlled. A compensation claim was awarded for the three days of work he had missed on account of his symptoms.

\section{CURRENT ADVICE}

The following 12 statements are reproduced with permission of the ACCP and CHEST (5):

1. In all individuals with new-onset or worsening asthma, take a history to screen for work-related asthma (occupational asthma and work-exacerbated asthma). Then confirm the diagnosis of asthma and investigate to determine whether the patient has work-related asthma, performing these tests whenever possible before advising the patient to change jobs.

2. In all individuals with suspected work-related asthma, obtain a history of job duties, exposures, industry, use of protective devices and/or equipment, and the presence of respiratory disease in coworkers and consult MSDSs, which list many recognized hazardous agents. Document the onset and timing of symptoms, medication use, and lung function, and their temporal relationship to periods at and away from work.

3. In individuals who have asthma not caused by work but have symptoms that subsequently worsen while working, consider the diagnosis of work-exacerbated asthma, which is usually based on changes in symptoms, medication use and/or lung function temporally related to work.

4. In individuals with suspected sensitizer-induced occupational asthma, in addition to carefully documenting the occupational history, perform additional objective tests when feasible (eg, serial peak flow recordings, serial methacholine challenges, immunological assessments, induced sputum testing and specific inhalation challenge) to improve the diagnostic probability.

5. In individuals with suspected work-related asthma who are currently working at the job in question, record serial measurements of peak flow as part of the diagnostic evaluation and ask the patient to record these optimally a minimum of four times daily, for at least two weeks at work and two weeks off work.

6. In individuals with suspected sensitizer-induced occupational asthma who are currently working at the job in question, obtain a methacholine challenge test or obtain comparable measures of nonspecific airway responsiveness during a working period and repeat it during a period (optimally at least two weeks) away from the work exposure to identify work-related changes.

7. In individuals with suspected sensitizer-induced occupational asthma, obtain immunological testing (skin prick test or in vitro specific immunoglobulin E assays) to identify sensitization to specific work allergens when these are technically reliable and available.

8. In individuals with suspected sensitizer-induced occupational asthma, conducting a specific inhalation challenge (where available) is suggested when the diagnosis or causative agent remains equivocal; however, this testing should only be performed in specialized facilities, with medical supervision throughout the testing.

9. For all individuals with work-related asthma, attempt more effective control of exposures. Remove patients with sensitizerinduced occupational asthma from further exposure to the causative agent in addition to other asthma management.

10. In individuals with irritant-induced or work-exacerbated asthma, the panel advises optimizing asthma treatment and reducing the exposure to relevant workplace triggers. 
If not successful, change to a workplace with fewer triggers is suggested to control asthma.

11. For workers who are potentially exposed to sensitizers or uncontrolled levels of irritants, the panel advises primary prevention through the control of exposures (eg, elimination, substitution, process modification, respirator use and engineering control).

12. An individual diagnosis of occupational asthma represents a potential sentinel health event:

- Evaluate the workplace to identify and prevent other cases of occupational asthma in the same setting; and

- For work environments with potential exposure to sensitizers the Panel advises secondary preventive measures including medical surveillance using tools such as questionnaires, spirometry, and where available, immunological tests.

\section{REFERENCES}

1. Tarlo SM, Boulet LP, Cartier A, et al. Canadian Thoracic Society guidelines for occupational asthma. Can Respir J 1998;5:289-300.

2. Brooks SM, Weiss MA, Bernstein IL. Reactive airways dysfunction syndrome (RADS). Persistent asthma syndrome after high level irritant exposures. Chest 1985;88:376-84.

3. Beach J, Russell K, Blitz S, et al. A systematic review of the diagnosis of occupational asthma. Chest 2007;131:569-78.

4. Henneberger PK. Work-exacerbated asthma. Curr Opin Allergy Clin Immunol 2007;7:146-51

5. Tarlo SM, Balmes J, Balkissoon R, et al. Diagnosis and management

of work-related asthma, American College of Chest Physicians Consensus Statement. Chest 2008;134:1S-41S. 


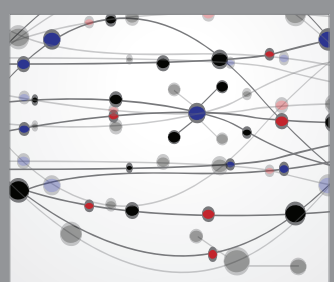

The Scientific World Journal
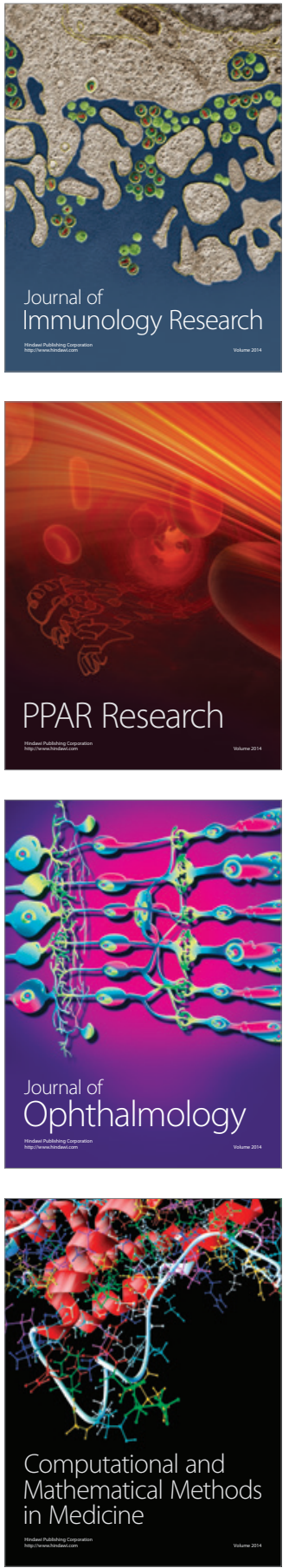

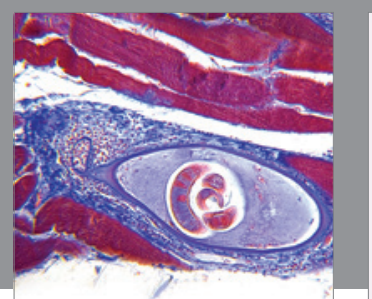

Gastroenterology Research and Practice

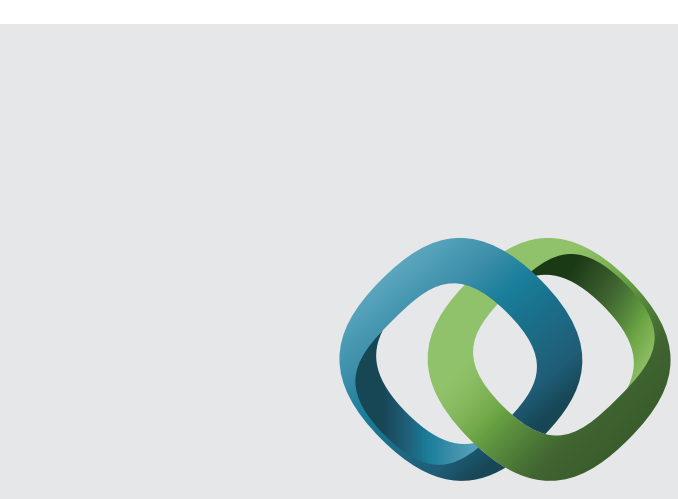

\section{Hindawi}

Submit your manuscripts at

http://www.hindawi.com
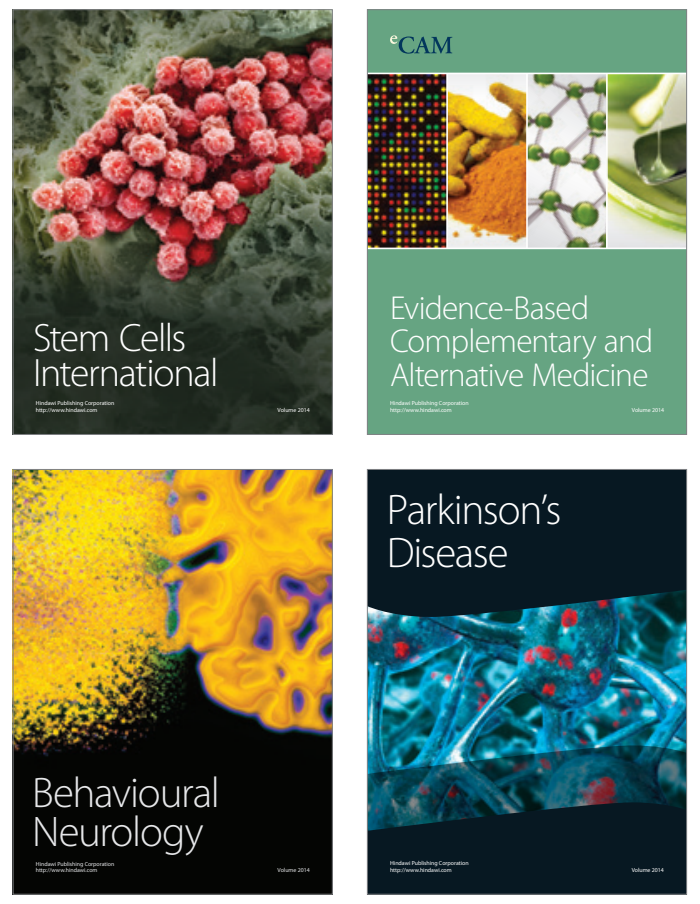
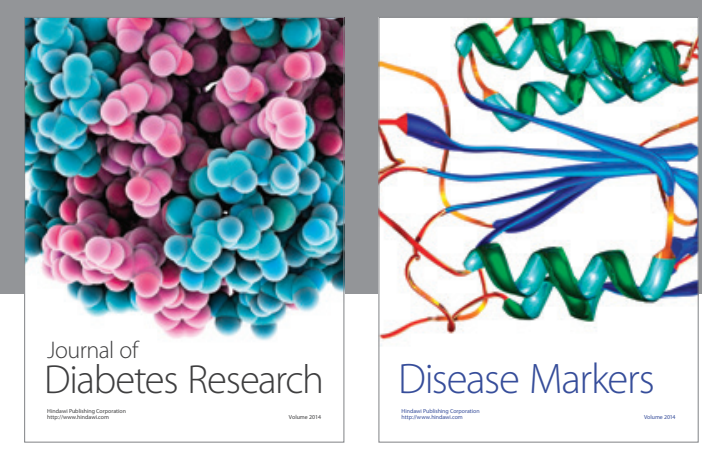

Disease Markers
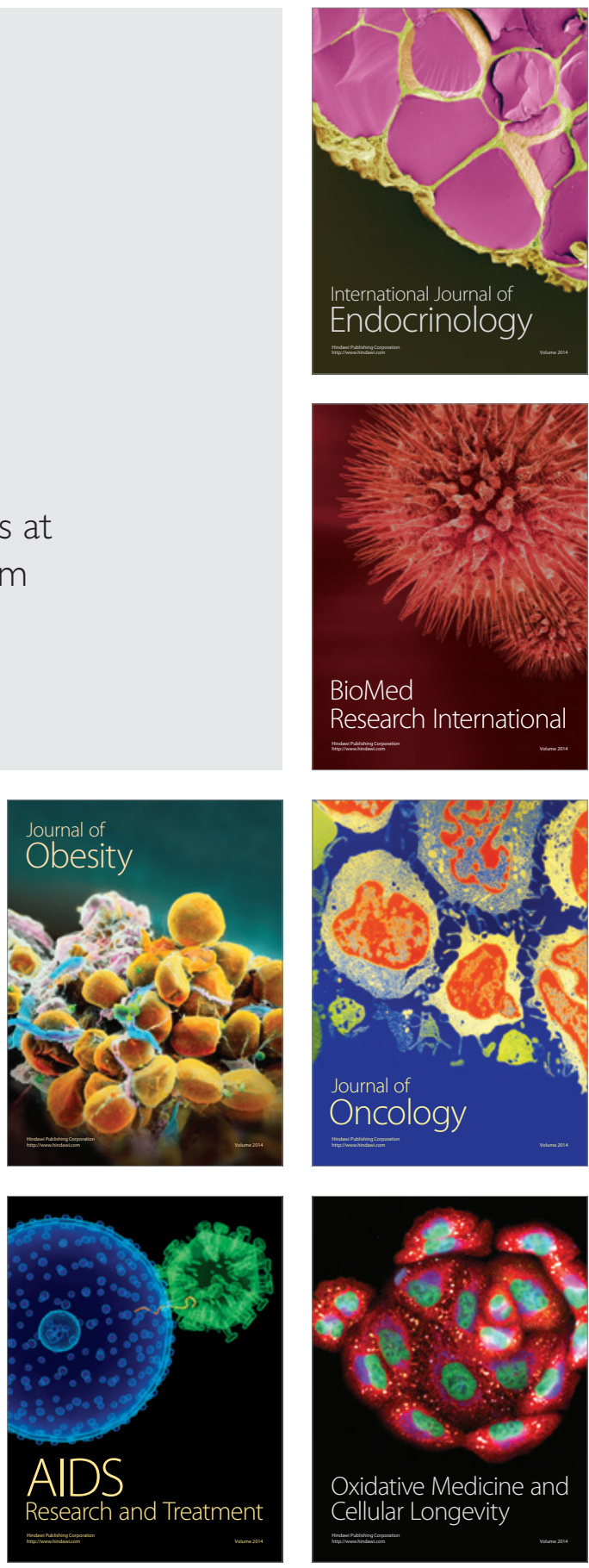